\title{
Manager's Leadership Is the Main Skill for Ambulatory Health Care Plan Success
}

\author{
Gustavo Horacio Marin, MD; Martin Silberman, MD; \\ Maria Virginia Colombo, MD, PhD; Belen Ozaeta, MD; \\ Jaime Henen, MD, PhD
}

\begin{abstract}
To demonstrate effectiveness of ambulatory health care plan implementation among institutions and variables associated with the differences observed. Randomized selection of primary health care (PHC) centers was done. Leadership ability of the plan manager was explored. Univariate/bivariate analyses were performed to observe correlation between variables. Two groups of PHC centers were established according to the efficacy of plan implementation: high and low performance. Differences between groups were observed (592\%-1023\% more efficacy in controls and practices; $P<.001)$. Leadership was responsible for the main differences observed. Leadership of manager for implementation of the health care plan was the major important variable to reach the best efficacy standards. Key words: health, leadership, model, Plan Nacer, service
\end{abstract}

$\mathbf{T}$ HE HEALTH CARE SYSTEM in Argentina is a mixed system, comprising 3 subsectors: state, social security, and private subsector (Belló \& Becerril-Montekio, 2011). The state subsector is organized on the basis of health care services centered in hospitals and primary care institutions. The health agents of this system are rewarded monthly for providing services only to the population that demands it (Marin et al., 2006, 2008, 2009, 2011).

Hence, this model has led the health care team not only to become careless about health care goals in relation to their patients but also

\section{Author Affiliations: Faculty of Medicine, National University of La Plata, La Plata, Argentina (Drs Marin and Silberman); and Secretaria de Salud, Municipalidad de La Plata, La Plata, Argentina (Drs. Colombo, Ozaeta and Henen).}

The authors have disclosed that they have no significant relationships with, or financial interest in, any commercial companies pertaining to this article.

Correspondence: Gustavo Horacio Marin, MD, Faculty of Medicine, National University of La Plata, 60 y 120, 1900-La Plata, Argentina (gmarin2009@ gmail.com).

DOI: $10.1097 / J A C .0000000000000014$ to refuse to attend to their demand, since the agents are paid with a fixed salary whether they attend their patients or not, discouraging all motivation, at least monetary incentives (Rosenberg \& Andersson, 2000; Vargas et al., 2008).

Plan Nacer is a proposal of the National Ministry of Health to solve the last problem, establishing the idea of granting monetary incentives to workers from the public primary health care (PHC) centers that meet with certain goals for their patients. These health team members must provide personalized medical examinations and controls, vaccination, or prevention activities to their target population.

The national government assigns a fixed amount of money per beneficiary who lives in the Buenos Aires territory and transfers the money of the millions of patients' beneficiaries of "Plan Nacer." Then, the provincial government transfers this money to PHC teams for each control, service, practice, or supply provided to patients from a list of patients under their care. This system forces the PHC agents to follow-up and provide medical checkups, vaccination, and prevention 
services to their beneficiaries. Each team receives monetary rewards if it complies with the expected controls and practices or is punished with a reduction in the money transfer if the goals are not achieved.

Today, 5 years have passed since the beginning of Plan Nacer. At this point, it is important to analyze some aspects regarding performance of the plan, achievements, obstacles, strengths, and weaknesses in order to understand whether that monetary incentive is enough to change health teams' attitude. A preliminary analysis detects a great heterogeneity in the results obtained by the different PHC centers. This aspect represents major interest, since PHC centers studied in this article have identical infrastructure, human resources, and target population.

This study was conducted to analyze the impact of monetary incentives on health teams for goals accomplished through testing the implementation of Plan Nacer in PHC institutions and determining the importance of medical officers' leadership skill in health program success.

\section{MATERIALS AND METHODS}

\section{Type of study}

This is a cohort study that compares the health care results obtained through a program that encourages PHC agents to meet health goals in a target population.

\section{Sample-universe-population goal}

The universe was made up of 45 municipal PHC centers located in La Plata, the state capital of Buenos Aires, that simultaneously started implementation of Plan Nacer in 2007. All PHC centers had similar facilities and human resources (similar number of health care professionals and medical and nonmedical specialty agents) and similar building structures. A random sample was obtained from these 45 PHC centers. The unit of analysis was each PHC center and the agents working in them. For the selection, the following formula was used to calculate the proportion of finite populations, determining an expected prevalence of incorrect behavior $(P)$ of $15 \%$, a $P$ of $5 \%$, and a sensibility of $20 \%$ :

$$
n=\frac{N Z^{2} P Q}{d^{2}(N-1)+Z^{2} P Q}
$$

\section{Period of time}

Primary health centers were analyzed during 5 years of implementation of the program from June 2007 to June 2012.

\section{Variables}

\section{Independent variable}

Leadership skill of the plan managers was objectively measured by a variable comprising 4 dimensions (general management ability, plan management, commitment, and interest). Table 1 shows the operationalization of this independent variable with the instruments and sources of correlation of the information. Each dimension was assigned a minimum of zero point and a maximum of 10 points that were derived from the average of instruments of measurement (each item was analyzed using a range between 0 and 3.33 points). The final score given to each manager was the average value obtained in each of the 4 dimensions (range, 0-10). The cutoff point between a good and a lousy manager was 6 points ( $>6$ was considered a good manager and $<6$ a lousy one).

\section{Dependent variables}

Fiscal reports of the plan are expressed in local currency "pesos" (invoiced amount and the total amount of money obtained by each center, and goods and acquisitions achieved with that money). Health care services and practices provided to the target population by PHC centers were codified and are shown in Tables 2 to 5 as health tracers. These health tracers were measured by the analysis of 3 reference months and were randomly selected from 1 year of the period of time of plan implementation. The months taken as reference were February, June, and October of 2009. Hence, each health institution had a number of services and practices given in these months to their beneficiaries. In this way, by assigning a cutoff point to each tracer, it 


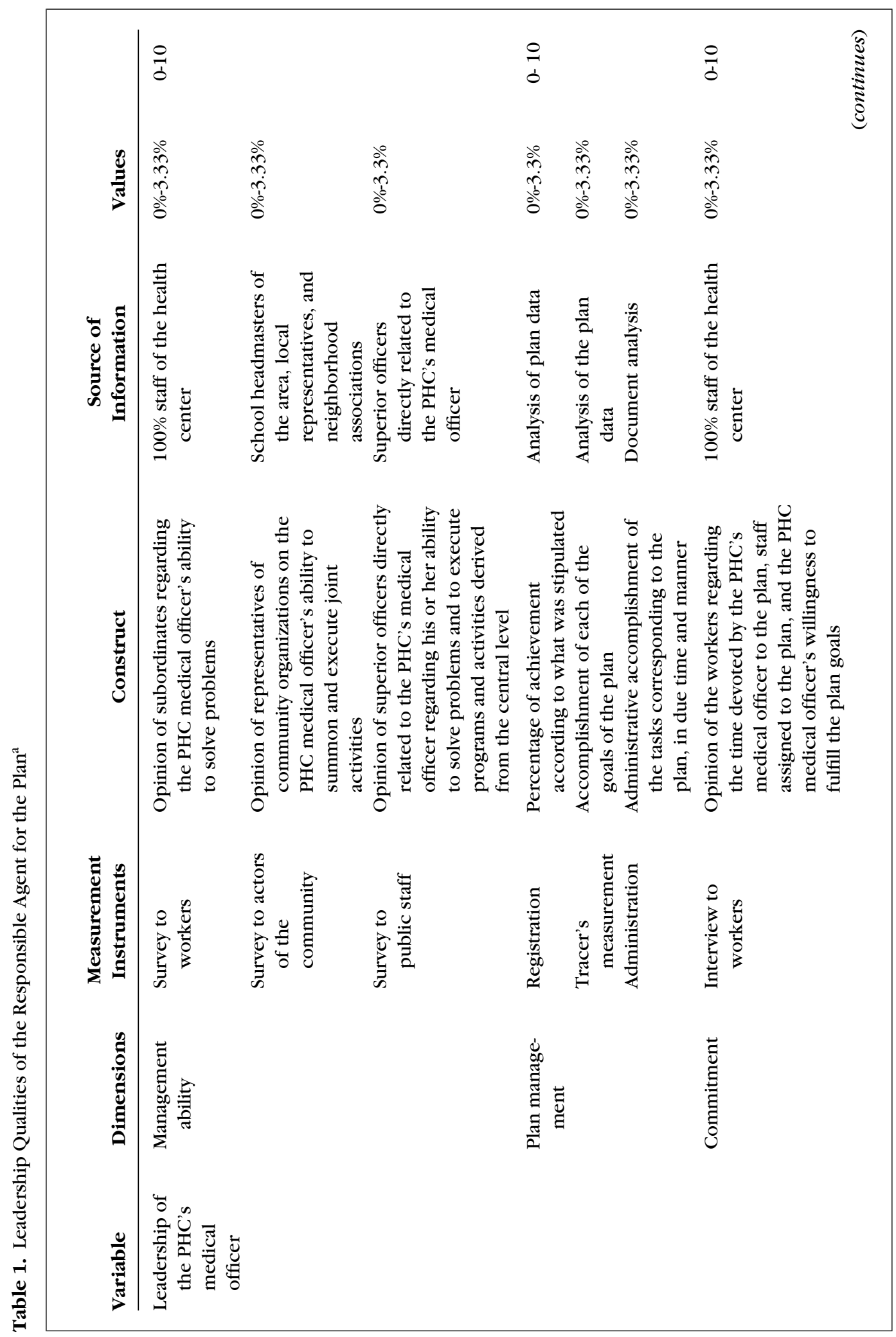




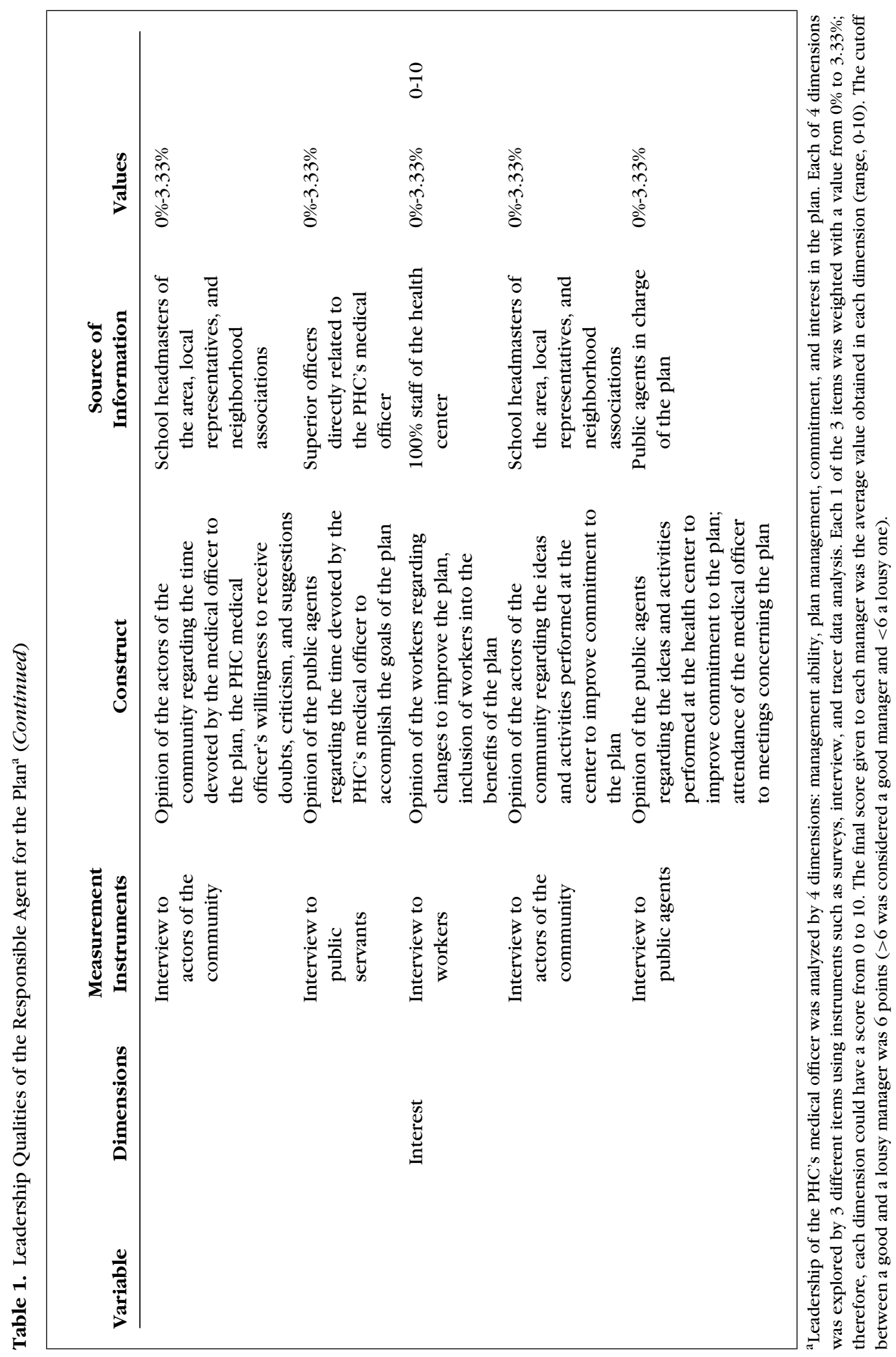




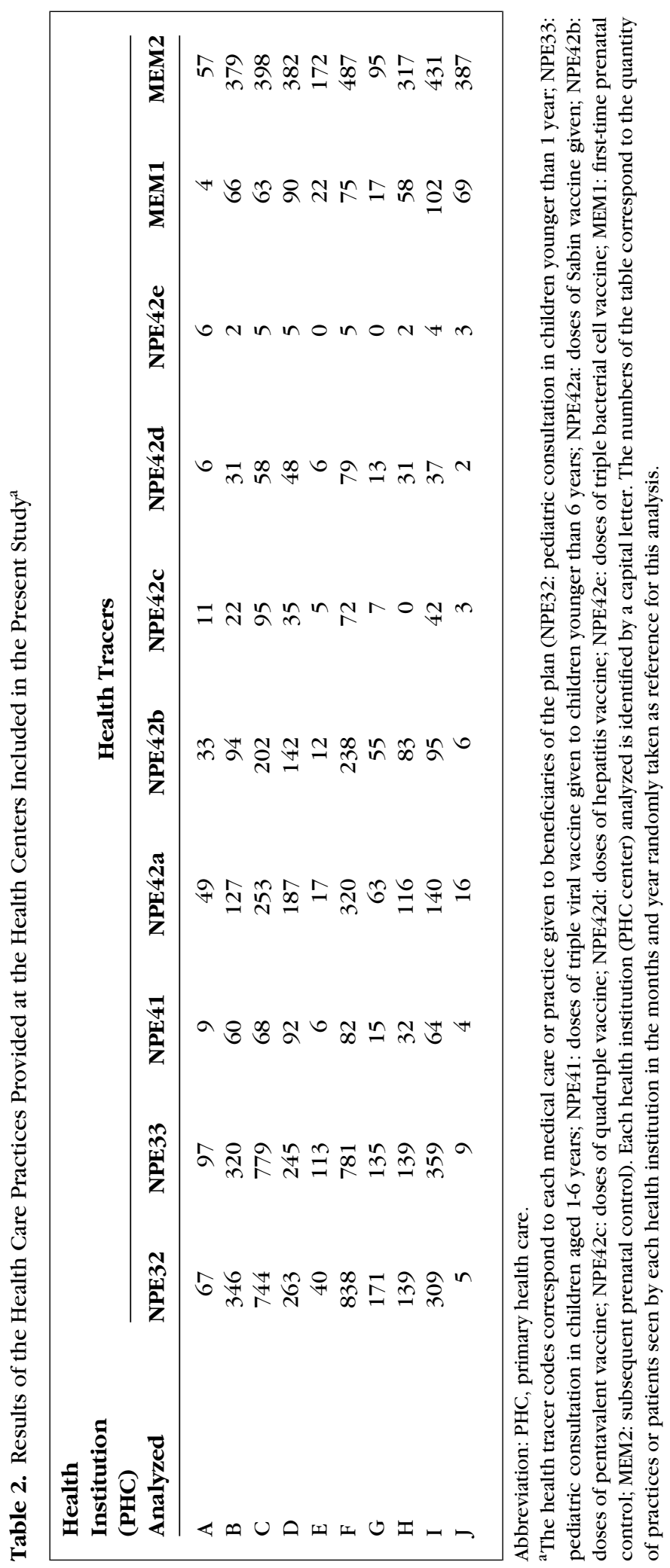




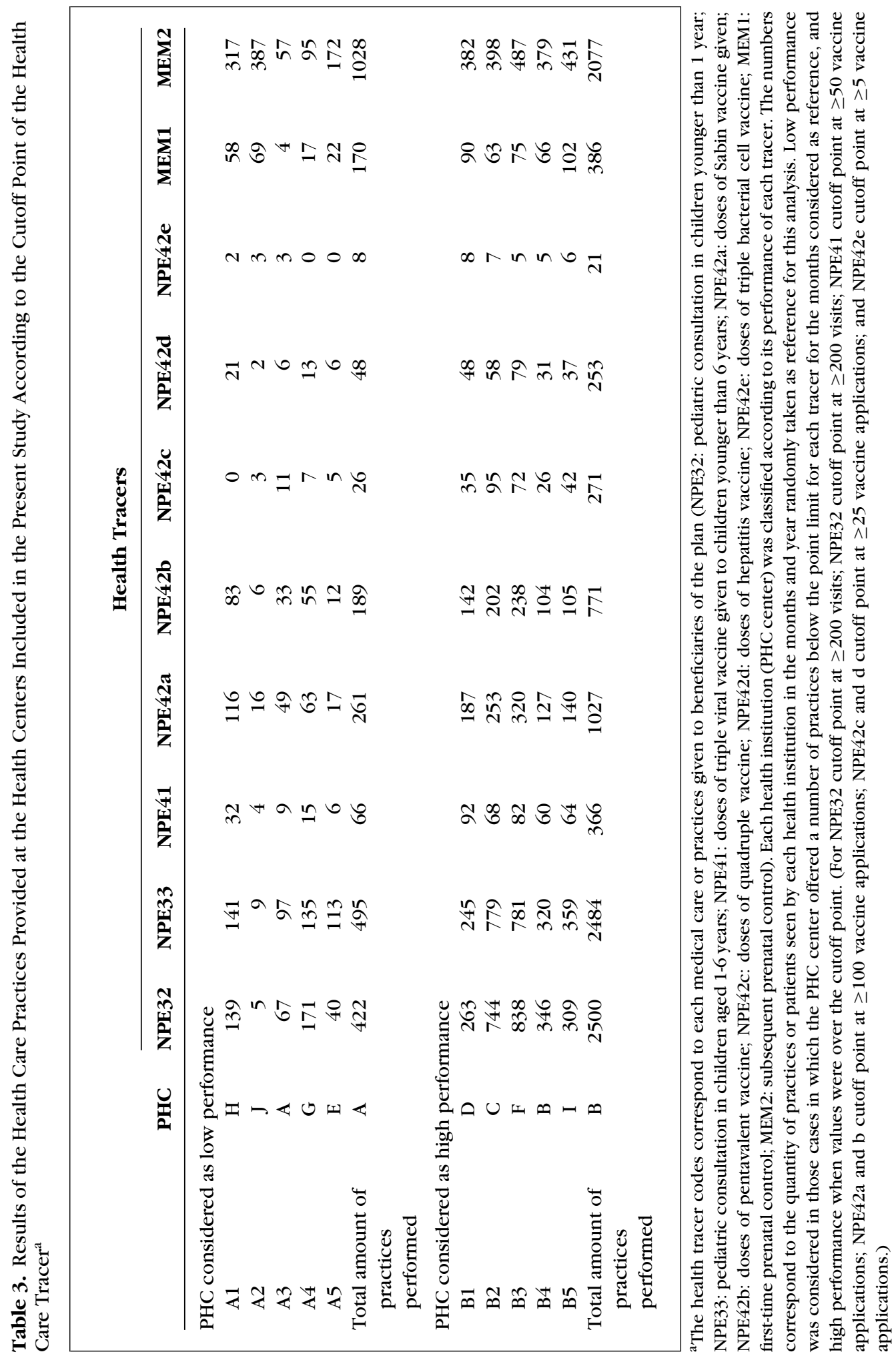


could be possible to classify PHC centers with a high or low performance according to expectations of the plan: NPE32 cutoff point at 200 or more visits; NPE32 cutoff point at 200 or more visits; NPE41 cutoff point at 50 or more vaccine applications; NPE42a and b cutoff point at 100 or more vaccine applications; NPE42c and d cutoff point at 25 or more vaccine applications; and NPE42e cutoff point at 5 or more vaccine applications.

\section{Control variables}

These variables include human resources and structure facilities in the centers under study and socioeconomic status of beneficiaries of the plan in each PHC center.

\section{Statistical analysis}

A univariate analysis was conducted to obtain results from each health center and then a bivariate analysis was performed to obtain correlation (Pearson) between the independent and independent variables. A linear regression analysis was also conducted to assess the predictive character of the independent variable.

\section{RESULTS}

Random sampling of 10 PHC centers was done by extracting data from the 45 PHC cen- ters belonging to the local health system. All of them presented the same building characteristics (in square meters and facilities) and similar human resources structure comprising 2 administrative assistants, 2 nurses, 3 doctors ( 2 general practitioners and 1 pediatrician), 1 dentist, 1 obstetrician, 1 psychologist, and 2 community health workers. All 10 PHC centers had similar amount and characteristics of the target population.

Health practices provided to the target population were irregular among PHC centers, especially regarding pregnancy controls, attention provided to children younger than 1 year, vaccination coverage, and health promotion workshops delivered to the target community (Table 2). Heterogeneity in the achievement of these practices and desired goals was clearly observed (Table 2).

Standard cutoff point established for each health tracer and goal enabled the categorization of PHC centers as either "high-performance" institution or "lowperformance" institution in relation to such cutoff points (Table 3). Comparison of both groups (low- and high-performance PHC centers) reveals differences (Table 4) in relation to each practice and tracer.

Table 4. Comparative Analysis of PHC Centers of High and Low Performance According to the Health Care Practices Provided ${ }^{\mathrm{a}}$

\begin{tabular}{|c|c|c|c|c|c|c|c|c|c|c|}
\hline \multirow[b]{2}{*}{ Type } & \multirow[b]{2}{*}{ NPE32 } & \multirow[b]{2}{*}{ NPE33 } & \multirow[b]{2}{*}{ NPE 41 } & \multicolumn{5}{|c|}{ NPE42 } & \multirow[b]{2}{*}{ MEM1 } & \multirow[b]{2}{*}{ MEM2 } \\
\hline & & & & $\mathbf{a}$ & $\mathbf{b}$ & c & d & $\mathbf{e}$ & & \\
\hline A & 422 & 493 & 66 & 261 & 189 & 26 & 58 & 11 & 170 & 1028 \\
\hline B & 2500 & 2484 & 366 & 1027 & 771 & 266 & 253 & 21 & 386 & 2077 \\
\hline Difference, \% & 592 & 504 & 554 & 393 & 408 & 1023 & 436 & 190 & 227 & 202 \\
\hline$P$ & $<.001$ & $<.001$ & .01 & .03 & .02 & $<.001$ & .02 & .7 & .04 & .04 \\
\hline
\end{tabular}

Abbreviation: PHC, primary health care.

${ }^{a}$ Each PHC center was classified according to its performance of each tracer (NPE32: pediatric consultation in children younger than 1 year; NPE33: pediatric consultation in children aged 1-6 years; NPE41: doses of triple viral vaccine given to children younger than 6 years; NPE42a: doses of Sabin vaccine given; NPE42b: doses of pentavalent vaccine; NPE42c: doses of quadruple vaccine; NPE42d: doses of hepatitis vaccine; NPE42e: doses of triple bacterial cell vaccine; MEM1: first-time prenatal control; MEM2: subsequent prenatal control). The numbers correspond to the average of each health care tracer provided by type A or B PHC centers in the months and year randomly taken as reference for this analysis. Low performance (grouped in type A institutions) was considered in those cases in which the PHC center offered a number of practices below the point limit for each tracer for the months considered as reference, and high performance (type B institutions) was assigned when values were over the cutoff point. Differences between low- and high-performance institutions are expressed as the percentage and statistically analyzed $P$ values. 
Regarding fiscal parameters of performance, Table 5 shows the main results for health centers, their total invoiced amount after 5 years of plan implementation, and the amount of money spent in acquisitions. These capabilities of the health institutions were presented next to the results obtained by the manager of each PHC center in each of the dimensions that measure his or her leadership capability (Table 5).

Main differences among PHC centers were then disclosed. While some PHC centers such as $\mathrm{F}$ and $\mathrm{I}$ showed high efficacy in care, controls, practices, or services given to their target population (and therefore monetarily rewarded for these services), other PHC centers had very low invoicing such as $\mathrm{A}, \mathrm{E}$, and J (Table 5). Similar differences regarding purchase of goods were observed, except for the centers with highest profits, which chose to assign high percentages of their funding to other items such as monetary incentives for their staff instead of allocating those funds to the purchase of goods. Note that these PHC capabilities correlate with PHC manager leadership skill (Table 5).

The Pearson correlation coefficient of variables "invoiced amount" and "leadership" was $0.948(P<.0001)$, whereas the correlation of the variable "amount spent in goods" with the same independent variable "leadership" showed a coefficient of $0.972(P<.0001)$.

The bivariate correlation analysis was then conducted among each of the dimensions included in the "leadership" variable (general management ability, plan management, commitment, and interest), with both the "amount spent in goods" and "invoiced amount" variables. The result of 8 correlations was positive, higher than 0.910, and all with levels of bilateral significance of less than .0001; therefore, a linear regression analysis was performed. The linear regression analysis revealed that for the "invoiced amount" dependent variable (model 1 ), the 4 predictive variables (management ability, plan management, commitment, and interest) accounted for $85 \%$ of the variance $\left(R^{2}\right.$ corrected $=$ 0.841 , with a significant relationship shown by analysis of variance $(P=.008)$. Determi- nation of the standardized regression coefficients, $\beta$, revealed that they did not reach an individual significance in the $t$ test, which allowed incorporating each value individually to the model. The same situation was observed when "amount spent in goods" was identified as the dependent variable; the 4 dimensions accounted for nearly $92 \%$ of the variance $\left(R^{2}\right.$ corrected $\left.=0.916\right)$, with a significant linear relationship shown by analysis of variance $(P=.002)$, although $\beta$ regression coefficient did not reach statistical significance at $5 \%$.

\section{CONCLUSIONS}

This study shows that PHC centers with the same staff and building characteristics had significant differences in the efficacy of practices provided to their target population, their goals achievements, and the cost recovery for those controls and practices provided to beneficiaries of the national plan (Plan Nacer) that aims to encourage health teams to work on the basis of results obtained.

A model that focuses on the leadership skill of agent manager of the plan in each PHC center comprising 4 main dimensions was developed. This analysis allows predicting with great precision the results obtained for a health care center according to the leadership characteristics of the PHC center plan's responsible officer.

It should be noted that all medical staff and managers of the plan in PHC centers had regularly attended training management courses conducted by the staff team of Plan Nacer; therefore, all of them had the same access to knowledge and understanding of the plan.

Notably, analysis of all the variables revealed that the higher management capability of the chief agent responsible for the PHC center, regardless the other variables, was the best element to implement the plan with efficacy.

This study could not conclude on the ability of each dimension to predict PHC center performance, possibly due to the sample size. Thus, in future assessments, a large number 


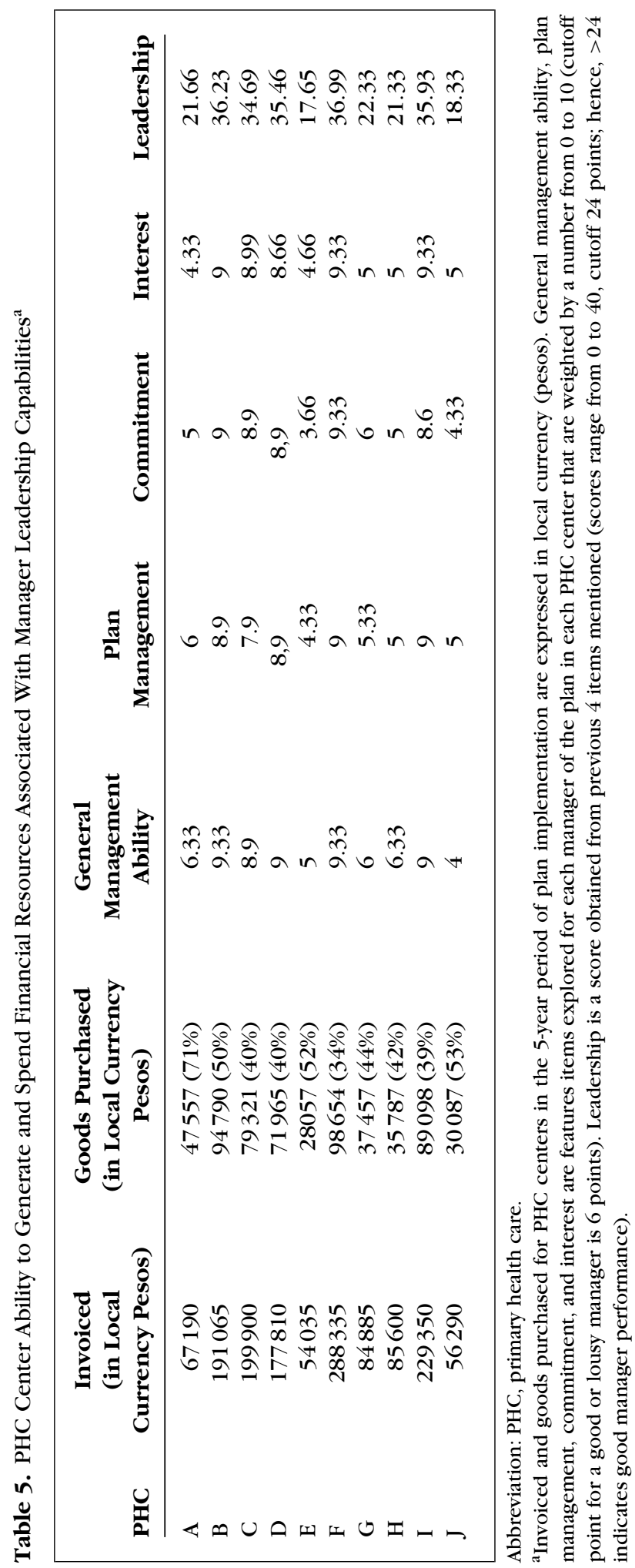


of PHC centers should be included to identify such situations.

However, within the field of analysis of health care programs, this study is able to show that the manager's leadership skill in PHC centers strongly determines the success or failure of the plan, independently of how good or bad is the drawing up of the program design. This is a topic of special interest to analyze the plan's responsible officer in each
PHC, since it has been demonstrated in our results that with same tools (structure, facilities, health team), the same health plan design, and even the same rewards for goals accomplished, results will be different among PHC centers based on the leadership skills (general management capability; plan management, motivation, commitment, and interest) of the local responsible agent of the plan in each PHC center.

\section{REFERENCES}

Belló, M., \& Becerril-Montekio, V. M. (2011). Sistema de Salud de Argentina. Salud Pública de Mexico, 52(2), 96-108.

Marin, G. H., Rivadulla, P., Vázquez, A., \& Juárez D, Grupo Interdisciplinario para la Salud. (2006). [Interdisciplinary health project: A model based in home care makes the difference]. Anales del Sistema Sanitario de Navarra, 29(1), 107-118.

Marin, G. H., Silberman, M., \& Etchegoyen, G. (2008). [A personalised health care programme (PANDELAS) operating in Buenos Aires, Argentina, during 2006]. Revista de Salud Pública, 10(2), 203-214.

Marin, G. H., Silberman, M., \& Sanguinetti, C. (2009). The quality of primary care health centres in Buenos Aires, Argentina. Quality in Primary Care, 17(4), 283-287.
Marin, G. H., Silberman, M., Uriarte, A., Sarijulis, M., Ozaeta, B., \& Henen, J. (2011). Healthcare model based on personalised attention: Impact on maternal mortality and health system quality. Quality in Primary Care, 19(5), 311-316.

Rosenberg, H., \& Andersson, B. (2000). Repensar la protección social en salud en América Latina y el Caribe. Revista Panamericana de Salud Pública, 8(1-2), 118-125.

Vargas, L., Vázquez Navarrete, M., de la Corte Molina, P., Mogollón Pérez, A., \& Unger, J. (2008) [Reform, equity, and efficiency of the healthcare systems in Latin America. An analysis to inform the Spanish aid. 2008 SESPAS Report]. Gaceta Sanitaria, 22, 223-229. 